\title{
High Behavioral Inhibition System/Behavioral Activation System Sensitivity, Childhood Emotional Neglect and Their Interaction as Possible Related Factors for Adult Attachment Style in Depression
}

\author{
Hyu Jung Huh', Bo Ram Jeong ${ }^{1}$, Ji Hyun Hwang ${ }^{2}$, and Jeong-Ho Chae ${ }^{2,3 凶}$ \\ ${ }^{1}$ Department of Psychiatry, Incheon St. Mary's Hospital, The Catholic University of Korea College of Medicine, Incheon, Republic of Korea \\ ${ }^{2}$ Catholic Emotion Research Laboratory, Catholic Biomedical Industrial Institute, Seoul, Republic of Korea \\ ${ }^{3}$ Department of Psychiatry, Seoul St. Mary's Hospital, The Catholic University of Korea College of Medicine, Seoul, Republic of Korea
}

Objective Individual differences in attachment insecurity are important in a broad range of mental health problems. However, few empirical studies have examined the clinical factors that contribute to individual differences in attachment style. This study examines the nature of interrelationships among adult attachment styles, sensitivities of behavioral activation system/behavioral inhibition system (BIS/BAS), and childhood trauma in patients with depressive disorders.

Methods Patients with depressive disorders $(\mathrm{n}=294)$ completed self-report questionnaires evaluating adult attachment style, childhood trauma, and BIS/BAS sensitivity. We performed multiple regression analyses to examine the associations between attachment style and other clinical factors, including childhood trauma and BIS/BAS sensitivity. We also conducted hierarchical regression analyses and simple slope analyses to examine the interaction between BIS/BAS sensitivity and childhood trauma.

Results The BAS sensitivity was negatively associated with attachment avoidance. The higher was the BIS/BAS sensitivity, the higher was the level of attachment anxiety. Among childhood trauma, emotional neglect contributed to both dimensions of insecure attachment. The interaction between BAS sensitivity and emotional neglect is significantly associated with attachment anxiety.

Conclusion This study used data regarding the interrelationship of childhood trauma and basic motivational systems to contribute to the understanding of adult insecure attachment behaviors, a risk factor for depression. Psychiatry Investig 2020;17(2):122-129

Key Words Attachment, Behavioral inhibition system, Behavioral activation system, Childhood trauma, Depression.

\section{INTRODUCTION}

Many prior studies have investigated the relationship between motivational systems and attachment, childhood trau$\mathrm{ma}$, and temperament. All of these behaviors influence different domains of mental health and general wellbeing. ${ }^{1,2}$ Insecure attachment, childhood trauma, low reward sensitivity, and behavioral inhibition have all been suggested to be important risk factors affecting the onset, duration, and prognosis of depression. ${ }^{3-9}$ However, few studies have clinically examined the inter-

Received: July 3, 2019 Revised: October 23, 2019

Accepted: November 7, 2019

$\triangle$ Correspondence: Jeong-Ho Chae, MD, PhD

Department of Psychiatry, Seoul St. Mary's Hospital, The Catholic University of Korea College of Medicine, 222 Banpo-daero, Seocho-gu, Seoul 06591, Republic of Korea

Tel: +82-2-2258-6083, Fax: +82-2-2258-3870, E-mail: alberto@catholic.ac.kr (c) This is an Open Access article distributed under the terms of the Creative Commons Attribution Non-Commercial License (https://creativecommons.org/licenses/bync/4.0) which permits unrestricted non-commercial use, distribution, and reproduction in any medium, provided the original work is properly cited. relationships between attachment, childhood trauma, and temperament. Therefore, this study examines the interrelationships among adult attachment styles, sensitivities of behavioral inhibition system/behavioral activation system (BIS/BAS), and childhood trauma.

Attachment theory postulates that individuals seek the company of others in stressful situations. However, there are individual differences with regard to whom the distressed person approaches or avoids in their attachment figure. ${ }^{10-12}$ Reinforcement sensitivity theory (RST) involves temperament and may deepen our understanding of these individual differences. ${ }^{13}$ The RST suggested that people differ in sensitivity and responsiveness of two fundamental motivational systems that are thought to determine behavioral response in threatening situations, the BIS/BAS. ${ }^{14}$ The BIS is a neural system that deals with threat-related information and triggers anxiety, arousal, and inhibition of the ongoing behavior. In contrast, the BAS is a neural system that process reward-relat- 
ed information and triggers positive feelings and approach behavior.

Dysregulation of these motivational systems may be related to difficulties with socio-emotional processing. ${ }^{15}$ In Ochsner's model, one of the main constructs of socio-emotional processing is the identification of social stimuli that lead to aversive or appetitive results. ${ }^{16}$ One study suggested that the quality of attachment relationships is related to increased vigilance to rejection and avoidance of social reinforcement. ${ }^{17}$ Attachment theory is also thought of as a theory of motivation. It postulates that accounts of behaviors are based on approach-avoidance motivation dynamics. Bowlby described avoiding threats or approaching the attachment figure as a "twin process of survival." Variations in this behavioral pattern characterize individual differences in attachment behavior. ${ }^{10}$ Therefore, an integrative study could further the understanding of the underlying motivational mechanisms of attachment styles. Several prior studies have suggested that both attachment anxiety and avoidance are associated with heightened responses to threatening stimuli, linking them to defensive motivations. ${ }^{18}$ Some empirical studies have supported the theory that attachment avoidance is negatively correlated with BAS sensitivity, and that attachment anxiety is positively associated with BIS sensitivity. ${ }^{11,19}$ However, most studies were performed in mentally healthy people. There are very few studies performed in clinical settings.

In addition to motivational system, childhood trauma, and especially that perpetrated by the primary caregiver, can be also critical to a child's attachment. ${ }^{20}$ Children who are exposed to maltreatment have been found to be more likely to have an insecure-disorganized type of attachment. Several empirical studies have previously suggested that childhood emotional trauma is associated with insecure attachment. ${ }^{21,22}$ Furthermore, in context of temperament-environment interaction, it would be possible that childhood emotional trauma may give an interaction effect on the relationship between motivation system and adult attachment style.

Based on theoretical background and previous studies, we examined the relationships between adult attachment style, childhood trauma, and BIS/BAS sensitivity in patients with depressive disorders and developed three hypotheses. First, the BAS sensitivity would be negatively correlated with attachment avoidance and positively correlated with attachment anxiety. In addition, the BIS sensitivity would be positively correlated with both dimensions of attachment insecurity. Based on this theory, individuals with a high BAS sensitivity would be likely to engage in approach rather than avoidance behavior in their relationships. In contrast, the BIS sensitivity is involved with emotional distress when potentially harmful events occur. ${ }^{14}$ Considering the vulnerability of increasing anxiety, arousal, and emotional instability in re- lationships, both dimensions of attachment insecurity would be positively correlated with BIS sensitivity. Our second hypothesis was that, among various types of childhood trauma, emotional trauma would be significantly associated with both attachment styles, as a caregiver's emotional sensitivity and response are important for shaping attachment style and security. Thirdly, we hypothesized that there would be a significant interaction effect of BIS/BAS sensitivity and childhood trauma on attachment style. Individuals with high BIS/ BAS sensitivity would suffer from more insecure attachment when exposed to severe childhood emotional trauma.

\section{METHODS}

\section{Participants}

We recruited patients who visited the Mood and Anxiety Disorders Unit at Seoul St. Mary's Hospital, The Catholic University of Korea between August 2011 and July 2014. All recruited patients had a principal diagnosis of nonpsychotic depressive disorder based on the DSM-IV diagnostic criteria. These diagnoses were made by a psychiatrist using diagnostic interviews from the Mini-International Neuropsychiatric Interview (M.I.N.I). ${ }^{23}$ Patients were eligible if they were $18-65$ years old and literate in Korean. The exclusion criteria included a lifetime diagnosis of psychotic disorder, bipolar disorder, mental retardation, and any mental disorder resulting from a general medical condition. A total of 364 outpatients who met the inclusion criteria participated in this study. Analyses were restricted to those who completed all study measures. Therefore, the final sample was comprised of 294 patients. All subjects provided written informed consent. The study protocol was approved by the Institutional Review Board of the Ethics Committee of Seoul St. Mary's Hospital at The Catholic University of Korea (KC09FZZZ0211).

\section{Measurements}

\section{Socio-demographics and depressive symptom severity}

During diagnostic interviews using the M.I.N.I, patients were asked about their demographic information, including years of formal education, marital status, and employment status. We assessed participant's depressive symptoms using the Korean version of the Beck Depression Inventory (BDI). ${ }^{24}$ In this study, the BDI (Cronbach's $\alpha=0.919$ ) scores showed good internal consistency.

\section{BIS/BAS}

We used the BIS/BAS to assess individual differences in the sensitivity of the behavioral activation system and behavioral inhibition system. ${ }^{14}$ The BIS/BAS scale consists of 20 
self-rated items using a 4-point Likert scale (1=very true for me, to $4=$ very false for me). The items were combined to compose one BIS scale, which addresses reactions to negative events, such as criticism. There were also three BAS scales, Drive, Fun Seeking, and Reward Responsiveness, related to responses to rewarding stimuli. In the present study, the items were grouped into used the two scales: BIS and BAS. The score of BAS were summed from three subscales of BAS, Drive, Fun Seeking and Reward Responsiveness. The internal consistency reliability coefficients for the BIS and BAS scales (Cronbach's alpha) were between 0.832 and 0.876 .

\section{Childhood trauma}

Childhood abuse and neglect were assessed using the Childhood Trauma Questionnaire (CTQ). ${ }^{25}$ This questionnaire is a 28 -item self-report inventory that assesses the following five types of potential trauma experienced by a child or teenager: emotional abuse, physical abuse, sexual abuse, emotional neglect, and physical neglect. The items are rated on a 5 -point frequency scale $(1=$ never true to $5=$ very often true). The scores were added to yield a total score for each type of trauma, ranging from 5 to 25 . Higher scores indicate greater severity. In this study, the total CTQ score displays good internal consistency (Cronbach's $\alpha=0.923$ ). The Cronbach's alpha values for emotional abuse, emotional neglect, physical abuse, physical neglect, and sexual abuse were 0.834 , $0.939,0.865,0.663$, and 0.836 , respectively.

\section{Adult attachment style}

We assessed the severity of the different styles of insecure attachment using the Experiences in Close Relationships Questionnaire (ECR). ${ }^{26}$ The ECR is a 36 -item questionnaire that assesses adult attachment using a 5-point Likert scale ( $1=$ strongly disagree to $5=$ strongly agree). Participants were asked to respond to the questionnaire while considering how they generally experienced their relationships with their partner. The items were grouped into two scales: attachment anxiety and attachment avoidance. In this study, the Cronbach's alpha values for the attachment anxiety and avoidance scales were 0.909 and 0.853 , respectively.

\section{Data analysis}

Our main predictive variables were the sensitivity levels of the behavioral inhibition system and the behavioral activation system. The moderating variables were four types of childhood trauma, and the dependent variables were attachment anxiety and attachment avoidance (Figure 1).

We obtained descriptive statistics via frequency analysis in order to examine the characteristics of the participants. To determine whether all of the data met the assumption of a normal distribution, we examined the skewness and kurtosis of the main variables. We found that the absolute values of skewness and kurtosis were not $\geq \pm 2$. We conducted multiple regression analyses to explore the associations between the two dimensions of adult attachment styles and other factors (demographic factors, depressive symptom severity, childhood trauma, and BIS/BAS system sensitivity).

To test for a moderation effect, we performed hierarchical regression analysis, as suggested by Aiken and West. ${ }^{27}$ When interaction terms are included in a regression model, the effect of multicollinearity may be problematic. Therefore, we produced an interaction term by mean-centering the sum of the scores of the predictive variables (BIS/BAS system sensitivity) and the moderating variable (childhood trauma). We first entered the predictive and moderating variables into the model. Next, we simultaneously included the predictive variables, moderating variable, and interaction terms to examine their effects on the dependent variables, attachment anxiety, and attachment avoidance. To examine the pattern of the moderation effect, we performed simple slope analysis. All analyses were performed using SPSS 22.0 (IBM Corp., Armonk, NY, USA).

\section{RESULTS}

\section{Participant characteristics}

Participant demographics are presented in Table 1. The mean participant age was $35.49( \pm 13.33)$ years, and $54.5 \%$ were female. A total of $38.9 \%$ participants were separated or divorced. The mean length of education was 13.53 years $( \pm 3.97)$. In the questionnaire, $30.5 \%$ of participants reported

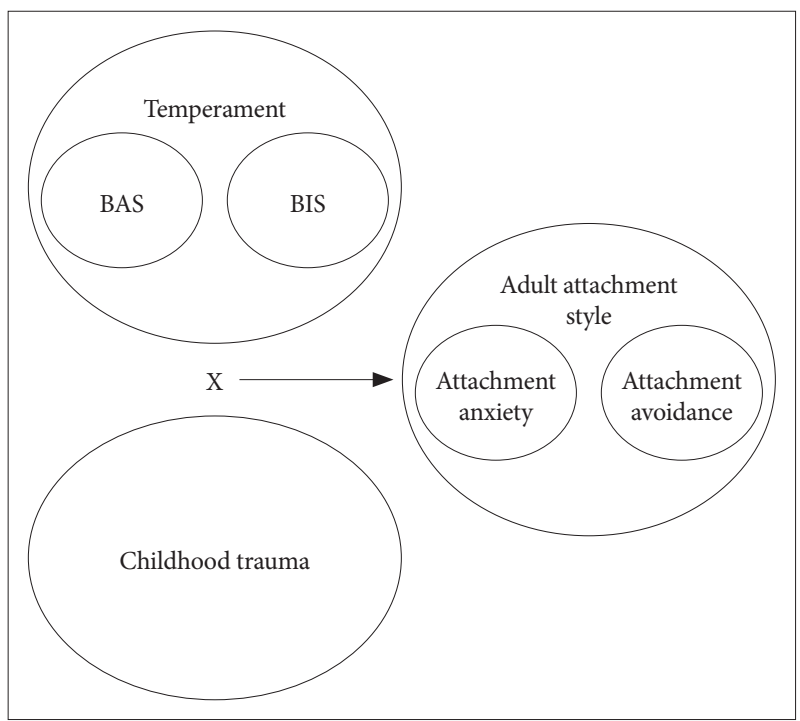

Figure 1. Hypothesized model about interrelation among BIS/ BAS sensitivity, childhood trauma and adult attachment style. BAS: behavioral activation system, BIS: behavioral inhibition system. 
unemployment. The mean BDI score was $26.00( \pm 12.27)$. The mean BAS and BIS subscores were $34.03( \pm 6.47)$ and $22.72( \pm 3.52)$, respectively. The mean CTQ total score was 45.27 ( \pm 15.79$)$. The mean subscores of emotional neglect, emotional abuse, physical neglect, physical abuse, and sexual

Table 1. Demographic characteristics of participants

\begin{tabular}{lc}
\hline \multicolumn{1}{c}{ Characteristic } & Mean \pm SD (\%) \\
\hline Age & $35.49 \pm 13.33$ \\
Gender (female) & $54.5 \%$ \\
Educational year & $13.53 \pm 3.97$ \\
Employment status (unemployment) & $69.5 \%$ \\
Marital status (married/cohabited) & $38.9 \%$ \\
Depression (BDI) & $26.00 \pm 12.27$ \\
Behavioral activation system (BAS) & $34.03 \pm 6.47$ \\
Behavioral inhibition system (BIS) & $22.72 \pm 3.52$ \\
Childhood trauma (CTQ) & $45.27 \pm 15.79$ \\
Emotional neglect (CTQ_EN) & $22.19 \pm 8.69$ \\
Emotional abuse (CTQ_EA) & $9.06 \pm 4.91$ \\
Physical neglect (CTQ_PN) & $8.12 \pm 3.46$ \\
Physical abuse (CTQ_PA) & $9.03 \pm 4.72$ \\
Sexual abuse (CTQ_SA) & $6.35 \pm 3.04$ \\
Attachment anxiety (ECR_anxiety) & $51.87 \pm 12.80$ \\
Attachment avoidance (ECR_avoidance) & $54.90 \pm 12.27$ \\
\hline
\end{tabular}

abuse were $22.19( \pm 8.69), 9.06( \pm 4.91), 8.12( \pm 3.46), 9.03$ $( \pm 4.72)$, and $6.35( \pm 3.04)$, respectively. The mean ECR anxiety subscore was $51.87( \pm 12.80)$, and the mean ECR avoidant subscore was $54.90( \pm 12.27)$.

\section{Correlations between attachment style and other factors}

Table 2 summarizes the result of multiple regression analyses regarding the associations between two dimensions of attachment styles and other clinical factors. Depressive symptom severity was positively correlated with degree of attachment anxiety $(\beta=0.150, p<0.05)$ and attachment avoidance $(\beta=0.152$, $\mathrm{p}<0.05)$. The BAS score was positively related to attachment anxiety $(\beta=0.162, \mathrm{p}<0.01)$, but negatively associated with attachment avoidance $(\beta=0.259, \mathrm{p}<0.001)$. The BIS subscore was positively correlated with attachment anxiety $(\beta=0.468$, $\mathrm{p}<0.001$ ). There was no significant association between BIS sensitivity and attachment avoidance. Among the four subtypes of childhood trauma, emotional neglect was the only type that was significantly related to attachment anxiety $(\beta=0.214, p<0.01)$ and attachment avoidance $(\beta=0.169$, $\mathrm{p}<0.05)$.

Table 2. Demographics, temperament, childhood trauma and other clinical factors associated with two dimensions of attachment insecurity

\begin{tabular}{|c|c|c|c|c|c|c|}
\hline & \multicolumn{3}{|c|}{ Attachment anxiety } & \multicolumn{3}{|c|}{ Attachment avoidance } \\
\hline & $\mathrm{B}$ & SE & $\beta$ & B & SE & $\beta$ \\
\hline \multicolumn{7}{|l|}{ Demographics } \\
\hline Age & -0.07 & 0.07 & 0.07 & -0.10 & 0.07 & -0.11 \\
\hline Gender (female) & -1.30 & 1.37 & -0.50 & -1.37 & 1.35 & -0.06 \\
\hline Educational year & -0.55 & 0.55 & -0.05 & 0.20 & 0.56 & 0.02 \\
\hline Employment status (unemployment) & 0.04 & 0.51 & 0.00 & 0.69 & 0.50 & 0.09 \\
\hline Marital status (married/cohabited) & -1.18 & 1.31 & -0.06 & 0.16 & 1.28 & 0.01 \\
\hline \multicolumn{7}{|l|}{ Clinical symptoms } \\
\hline Depression (BDI) & $0.17^{*}$ & 0.07 & 0.15 & $0.14^{*}$ & 0.06 & 0.15 \\
\hline \multicolumn{7}{|l|}{ Temperament } \\
\hline Behavioral activation system (BAS) & $0.34^{*}$ & 0.11 & 0.16 & $-0.44^{\dagger}$ & 0.11 & -0.26 \\
\hline Behavioral inhibition system (BIS) & $1.77^{\dagger}$ & 0.22 & 0.47 & 0.10 & 0.21 & 0.03 \\
\hline \multicolumn{7}{|l|}{ Childhood trauma } \\
\hline Emotional neglect (CTQ_EN) & $0.33^{*}$ & 0.11 & 0.21 & $0.22^{*}$ & 0.10 & 0.17 \\
\hline Emotional abuse (CTQ_EA) & 0.04 & 0.20 & 0.02 & 0.10 & 0.20 & 0.05 \\
\hline Physical neglect (CTQ_PN) & -0.28 & 0.25 & -0.07 & 0.40 & 0.24 & 0.13 \\
\hline Physical abuse (CTQ_PA) & -0.16 & 0.17 & -0.06 & -0.03 & 0.17 & -0.01 \\
\hline Sexual abuse (CTQ_SA) & 0.05 & 0.24 & 0.01 & 0.10 & 0.23 & 0.03 \\
\hline
\end{tabular}


Table 3. Interaction effect of behavioral activation system/behavioral inhibition system and childhood emotional neglect on two dimensions of attachment insecurity

\begin{tabular}{|c|c|c|c|c|c|c|c|c|c|c|c|c|}
\hline & \multicolumn{6}{|c|}{ Attachment anxiety } & \multicolumn{6}{|c|}{ Attachment avoidance } \\
\hline & B & $\beta$ & $\mathrm{t}$ & $\mathrm{R}^{2}$ & $\Delta \mathrm{R}^{2}$ & $\mathrm{~F}$ & B & $\beta$ & $\mathrm{t}$ & $\mathrm{R}^{2}$ & $\Delta \mathrm{R}^{2}$ & $\mathrm{~F}$ \\
\hline Constant & 52.13 & & 79.53 & 0.25 & 0.02 & $23.74^{\dagger}$ & 54.69 & & 96.62 & 0.23 & 0.00 & $21.67^{\dagger}$ \\
\hline Depression & $0.45^{\dagger}$ & 0.42 & 8.09 & & & & $0.22^{\dagger}$ & 0.24 & 4.58 & & & \\
\hline $\begin{array}{l}\text { Behavioral } \\
\text { activation system }(\mathrm{X})\end{array}$ & $0.39^{\dagger}$ & 0.19 & 3.68 & & & & $-0.44^{\dagger}$ & -0.26 & -5.15 & & & \\
\hline $\begin{array}{l}\text { Childhood } \\
\text { emotional neglect }(Z)\end{array}$ & $0.24^{*}$ & 0.15 & 2.98 & & & & $0.30^{\dagger}$ & 0.23 & 4.39 & & & \\
\hline $\mathrm{XZ}$ & $0.03^{*}$ & 0.14 & 2.71 & 0.27 & & & -0.00 & -0.02 & -0.38 & 0.23 & & \\
\hline Constant & 52.02 & & 85.81 & 0.38 & 0.00 & $45.46^{\dagger}$ & 54.50 & & 95.00 & 0.18 & 0.01 & $16.83^{\dagger}$ \\
\hline Depression & $0.20^{\dagger}$ & 0.19 & & & & & $0.21^{\dagger}$ & 0.24 & 3.97 & & & \\
\hline $\begin{array}{l}\text { Behavioral } \\
\text { inhibition system }(\mathrm{X})\end{array}$ & $1.75^{\dagger}$ & 0.49 & 9.22 & & & & 0.20 & 0.07 & 1.12 & & & \\
\hline $\begin{array}{l}\text { Childhood } \\
\text { emotional neglect }(Z)\end{array}$ & $0.20^{*}$ & 0.14 & 2.84 & & & & $0.34^{\dagger}$ & 0.27 & 5.01 & & & \\
\hline $\mathrm{XZ}$ & 0.00 & 0.00 & 0.10 & 0.38 & & & 0.04 & 0.10 & 1.84 & 0.19 & & \\
\hline
\end{tabular}

${ }^{*} \mathrm{p}<0.05,{ }^{\dagger} \mathrm{p}<0.01$

Table 4. Simple slope analysis about moderation effect of emotional neglect in the relationship between BAS sensitivity and attachment anxiety

\begin{tabular}{lccccc}
\hline \multicolumn{1}{c}{ Emotional neglect } & $\mathrm{b}$ & $\mathrm{s} . \mathrm{e}$ & $\mathrm{t}$ & $\mathrm{LLCI}(\mathrm{b})$ & $\mathrm{ULCI}(\mathrm{b})$ \\
\hline$-1 \mathrm{SD}$ & 0.12 & 0.16 & 0.75 & -0.19 & 0.43 \\
$\mathrm{M}$ & 0.39 & 0.11 & 3.71 & 0.18 & 0.60 \\
$+1 \mathrm{SD}$ & 0.66 & 0.13 & 5.09 & 0.41 & 0.92 \\
\hline
\end{tabular}

\section{Moderating effect of childhood trauma on the relationship between attachment style and BIS/BAS system sensitivity}

Based on the results of multiple regression analyses, we analyzed the moderating effect of emotional neglect on the relationship between BIS/BAS sensitivity and attachment style (Table 3).

The moderating effect of emotional neglect was significant in the relationship between BAS sensitivity and attachment anxiety $(\beta=0.140, p<0.01)$. To examine the pattern of the moderating effect, we calculated the dependent value according to three different levels of childhood emotional neglect (Mean, Mean+1SD, Mean-1SD) using regression equations (Table 4, Figure 2). There was a significantly positive association between BAS sensitivity and attachment anxiety in groups with high $[\mathrm{b}=0.66, \mathrm{p}<0.01,95 \% \mathrm{CI}(0.41,0.92)]$ and moderate $[\mathrm{b}=0.39, \mathrm{p}<0.01,95 \% \mathrm{CI}(0.18,0.59)]$ levels of childhood emotional neglect.

\section{DISCUSSION}

Prior evidence suggests that individual differences in attach-

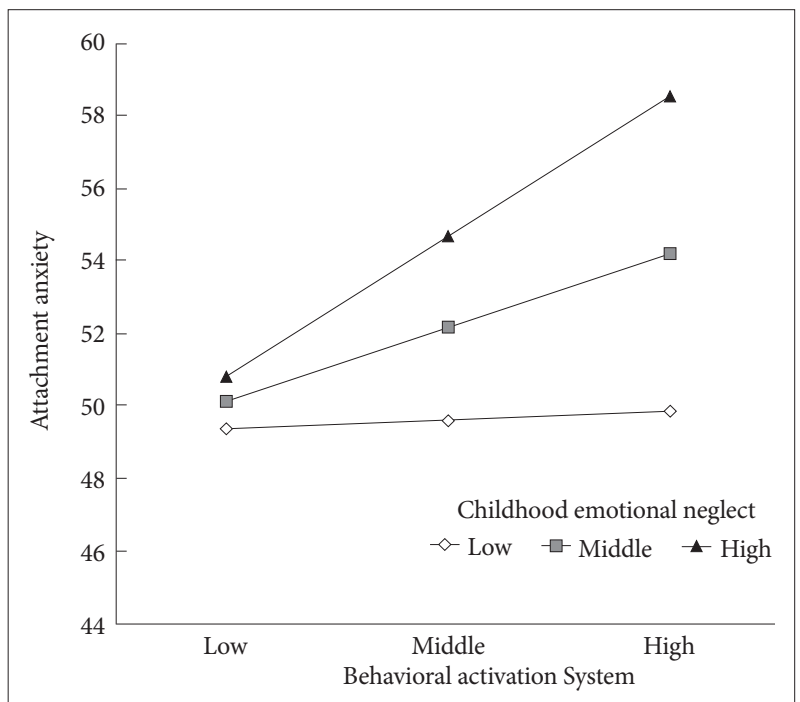

Figure 2. Interaction effect of BAS sensitivity and childhood emotional neglect on adult attachment style.

ment patterns are important factors that affect widespread mental health problems, including depression. However, there was previously no information regarding which factors affect an individual's attachment pattern. Several factors, including 
temperament (such as BIS/BAS sensitivity) and early life traumatic experience, have been previously investigated with mixed results. ${ }^{18,19}$ Based on this background, our study investigated the interrelationships among BIS/BAS sensitivity, childhood trauma, and adult attachment styles.

We found that attachment avoidance was only negatively correlated with BAS sensitivity. In contrast, attachment anxiety was positively correlated with both BIS and BAS sensitivity. The negative association between BAS sensitivity and attachment avoidance was consistent with the findings of several previous findings. ${ }^{18,19}$ Attachment avoidance was associated with the reduction of positive emotional experiences, devaluation of intimate relationships, ${ }^{28}$ and lower satisfaction withrelationships. ${ }^{11}$ These findings suggest that low sensitivity to rewards extends to the evaluation of one's attachment figure as less rewarding. This evaluation may be linked to the avoidant attachment's discomfort with intimacy.

In partial support of the hypothesis and previous findings, attachment anxiety was positively correlated with both BIS and BAS sensitivity. Previous studies suggested that BIS sensitivity is more strongly associated with attachment anxiety than it is to attachment avoidance. This finding is also is consistent with our results. ${ }^{29,30}$ Furthermore, previous studies found that attachment anxiety was related to more sensitive threat perception in relationships and greater ambivalence. In contrast, attachment avoidance was associated with low sensitivity to reward perception and decreased level of ambivalence. ${ }^{29}$ However, the previous findings regarding attachment and BAS sensitivity were inconsistent. In one study, attachment anxiety appeared to be weakly negatively associated with BAS sensitivity. ${ }^{18}$ Consistently, other studies have suggested that BAS sensitivity and attachment anxiety arepositivelycorrelated. ${ }^{19}$ Individuals with high levels of attachment anxiety are inclined to attempt to resolve relational problems, using both approach and distancing strategies. ${ }^{31,32}$ Such tendencies of an anxious attached person might be associated with a high sensitivity of both BIS/BAS. In contrast, the literature consistently and specifically suggests that people with avoidant attachment seek interpersonal distance in stressful or threatening situations. Such characteristics of avoidant attachment might be specifically associated with low sensitivity of the BAS.

Emotional neglect was the only type of childhood trauma that was significantly associated with both dimensions of insecure attachment styles. Emotional neglect occurs when a caregiver overlooks the signs that a child needs comfort or attention. It includes a range of behaviors including withholding love, constant belittling, denying needs for interacting, failing to express positive feelings to a child, and refusing to provide necessary psychological care. ${ }^{33}$ Some theorists have suggested that childhood emotional neglect can have particu- lar psychological meanings, such as rejection and abandonment by the parent as a key attachment figure. In contrast, abusive trauma does not have these psychological meanings. ${ }^{34}$ Such negative interactions with parents can leave a child feeling uncertain about the availability of a protective figure in times of trouble. ${ }^{10}$ The internal working model based on early neglect experience may be linked to insecure attachment. Several empirical studies have suggested that childhood emotional trauma is a vulnerable factor for insecure attachment. However, there are mixed results regarding whether specific types of childhood trauma have different effects on attachment anxiety and attachment avoidance. Several community studies have suggested that childhood emotional neglect is related to anxiety and depressive symptoms, mediated by attachment anxiety. ${ }^{33,35,36}$ Other studies have reported that emotional abuse was associated with schizotypy and partially mediated by both dimensions of insecure attachment. ${ }^{37}$ Considering that childhood emotional neglect was a more important factor in adulthood depression than were other types of childhood trauma, ${ }^{38,39}$ the participants' characteristics (potentially with clinically significant depressive symptoms) may have influenced our results. Further studies are needed to investigate how specific types of childhood trauma are related to attachment style in individuals with clinically significant mental illness.

Our findings suggest that individuals with high BAS sensitivity are more susceptible to anxious attachment styles under childhood emotional neglect. Inferring the reinforcement sensitivity theory, individuals with high BAS sensitivity tend to have reward-guided approach behavior. ${ }^{13}$ Under a severely emotionally neglected environment in which there are little opportunities to receive positive rewards, individuals may suffer from severe distress. This distressful foundation can cause such individuals to lose confidence that they will have a protective figure during stressful times. This thinking ultimately creates attachment anxiety. To the best of our knowledge, no prior studies have examined the interaction effect between BIS/BAS sensitivity and childhood traumatic experience on adult attachment styles. A larger, longitudinal study is needed to confirm the interrelationship among BIS/BAS sensitivity, childhood trauma, and adult attachment style.

\section{Limitations}

This study has several limitations. First, this was a cross-sectional study that concurrently assessed measurements. To establish causal relationships, there is a need for future longitudinal studies that follow children who are experiencing early life traumas. In particular, prospective studies that serially assess early childhood temperament, adulthood attachment style, and mental health outcomes would be informative. Another 
limitation of this study is that all variables, including childhood trauma, were assessed with self-reports. It is possible that depressive symptoms distorted the mental representations of patients' temperament, attachment styles, and memories of trauma. Furthermore, the reliability of the childhood trauma questionnaire subscore for physical neglect was limited in the present study. Prior studies found similar results regarding the internal consistency of the physical neglect subscore. Therefore, our results should be interpreted with caution. Third, we did not evaluate other factors related to childhood trauma, such as trauma timing or length or the victims' relationships with the perpetrators. Such factors may also influence current symptom severity.

\section{Conclusion}

Despite its limitations, this study provides interesting clinical results regarding the interrelationship of temperament, early life trauma, and adult attachment styles. Specifically, lower BAS sensitivity characterizes adult attachment avoidance, while greater BIS/BAS sensitivity was linked to attachment anxiety. Among childhood trauma, emotional neglect contributed to both dimensions of insecure attachment. Our results support a model in which the interaction effect of BAS sensitivity and emotional neglect is related to adult attachment style. These findings affirm the links among more basic motivational systems, early traumatic experience, and attachment behavioral patterns. Therefore, these results deepen the understanding of individual differences in adult attachment styles from a temperament-traumatic environment standpoint.

\section{Acknowledgments}

This study was supported by a grant of the Korea Health Technology R\&D Project through the Korea Health Industry Development Institute (KHIDI), funded by the Ministry of Health \& Welfare, Republic of Korea (grant number: HL19C0007).

\section{Conflicts of Interest}

The authors have no potential conflicts of interest to disclose.

\section{Author Contributions}

Conceptualization: Hyu Jung Huh, Jeong-Ho Chae. Data curation: JeonHo Chae. Formal analysis: Hyu Jung Huh, Bo Ram Jeong, Ju Hyun Hwang. Funding acquisition: Jeong-Ho Chae. Investigation: Hyu Jung Huh, Bo Ram Jeong, Ji Hyun Hwang, Jeong-Ho Chae. Project administration: JeongHo Chae. Resources: Jeong-Ho Chae. Software: Jeong-Ho Chae. Supervision: Jeong-Ho Chae. Validation: Jeong-Ho Chae. Visualization: Hyu Jung Huh. Writing—original draft: Hyu Jung Huh. Writing-review \& editing: Bo Ram Jeong, Ji Hyun Hwang, Jeong-Ho Chae.

\section{ORCID iDs}

Hyu Jung Huh

Bo Ram Jeong

Ji Hyun Hwang

Jeong-Ho Chae https://orcid.org/0000-0001-8050-9189

https://orcid.org/0000-0002-2399-4883

https://orcid.org/0000-0003-1553-3857

https://orcid.org/0000-0002-6070-9324

\section{REFERENCES}

1. Lieberman AF, Van Horn P. Psychotherapy with Infants and Young Children: Repairing the Effects of Stress and Trauma on Early Attachment: New York, NY: Guilford Press; 2008.

2. Spratt EG, Friedenberg S, LaRosa A, Bellis MDD, Macias MM, Summer AP, et al. The effects of early neglect on cognitive, language, and behavioral functioning in childhood. Psychology 2012;3:175-182.

3. Corcoran M, McNulty M. Examining the role of attachment in the relationship between childhood adversity, psychological distress and subjective well-being. Child Abuse Negl 2018;76:297-309.

4. Ju S, Lee Y. Developmental trajectories and longitudinal mediation effects of self-esteem, peer attachment, child maltreatment and depression on early adolescents. Child Abuse Negl 2018;76:353-363.

5. Lee DG, Park JJ, Bae BH, Lim HW. Moderating effects of preventionfocus on the paths from two insecure attachment dimensions to depression. J Psychol 2018:1-13.

6. Nowakowski-Sims E, Rowe A. The relationship between childhood adversity, attachment, and internalizing behaviors in a diversion program for child-to-mother violence. Child Abuse Negl 2017;72:266-275.

7. Li Y, Xu Y, Chen Z. Effects of the behavioral inhibition system (BIS), behavioral activation system (BAS), and emotion regulation on depression: a one-year follow-up study in Chinese adolescents. Psychiatry Res 2015;230:287-293.

8. Struijs SY, Lamers F, Vroling MS, Roelofs K, Spinhoven P, Penninx B. Approach and avoidance tendencies in depression and anxiety disorders. Psychiatry Res 2017;256:475-481.

9. Wang X, Zhou X, Dai Q, Ji B, Feng Z. The Role of Motivation in cognitive reappraisal for depressed patients. Front Hum Neurosci 2017;11:516.

10. Bowlby J. Attachment and Loss. New York, NY: Basic Books; 1980.

11. Mikulincer M, Shaver PR. Attachment in Adulthood: Structure, Dynamics, and Change. New York, NY: Guilford Press; 2007.

12. Shaver PR, Mikulincer M. Attachment-related psychodynamics. Attach Hum Dev 2002;4:133-161.

13. Gray JA. The Neuropsychology of Anxiety: An Enquiry into the Functions of the Septo-Hippocampal System. New York, NY: Clarendon Press/ Oxford University Press; 1982.

14. Carver CS, White TL. Behavioral inhibition, behavioral activation, and affective responses to impending reward and punishment: The BIS/ BAS Scales. J Pers Soc Psychol 1994;67:319-333.

15. Monteleone AM, Cardi V, Volpe U, Fico G, Ruzzi V, Pellegrino F, et al. Attachment and motivational systems: relevance of sensitivity to punishment for eating disorder psychopathology. Psychiatry Res 2017;260: 353-359.

16. Ochsner KN. The social-emotional processing stream: five core constructs and their translational potential for schizophrenia and beyond. Biol Psychiatry 2008;64:48-61.

17. Cardi V, Di Matteo R, Corfield F, Treasure J. Social reward and rejection sensitivity in eating disorders: an investigation of attentional bias and early experiences. World J Biol Psychiatry 2013;14:622-633.

18. Jiang Y, Tiliopoulos N. Individual differences in adult attachment and reinforcement sensitivity. Pers Individ Dif 2014;68:205-210.

19. Meyer B, Olivier L, Roth DA. Please don't leave me! BIS/BAS, attachment styles, and responses to a relationship threat. Pers Individ Dif 2005;38:151-162.

20. Carlson V, Cicchetti D, Barnett D, Braunwald KG. Finding Order in Disorganization: Lessons from Research on Maltreated Infants' Attachments to their Caregivers. In: Cicchetti D, Carlson V, Editors. Child Maltreatment: Theory and Research on the Causes and Consequences of Child Abuse and Neglect. New York, NY: Cambridge University Press, 1989, p.494-528.

21. Pearce J, Simpson J, Berry K, Bucci S, Moskowitz A, Varese F. Attachment and dissociation as mediators of the link between childhood trauma and psychotic experiences. Clin Psychol Psychother 2017; 24:1304-1312. 
22. Cohen LJ, Ardalan F, Tanis T, Halmi W, Galynker I, Von Wyl A, et al. Attachment anxiety and avoidance as mediators of the association between childhood maltreatment and adult personality dysfunction. Attach Hum Dev 2017;19:58-75.

23. Sheehan DV, Lecrubier Y, Sheehan KH, Amorim P, Janavs J, Weiller E, et al. The Mini-International Neuropsychiatric Interview (M.I.N.I): the development and validation of a structured diagnostic psychiatric interview for DSM-IV and ICD-10. J Clin Psychiatry 1998;59:22-33.

24. Beck AT, Ward CH, Mendelson M, Mock J, Erbaugh J. An inventory for measuring depression. Arch Gen Psychiatry 1961;4:561-571.

25. Bernstein D, Fink L. Childhood Trauma Questionnaire Manual. San Antonio: The Psychological Corporation; 1998.

26. Wei M, Russell DW, Mallinckrodt B, Vogel DL. The Experiences in Close Relationship Scale (ECR)-short form: reliability, validity, and factor structure. J Pers Assess 2007;88:187-204.

27. Aiken LS, West SG. Multiple Regression: Testing and Interpreting Onteractions. Thousand Oaks, CA: Sage Publications, Inc; 1991.

28. Shiota MN, Keltner D, John OP. Positive emotion dispositions differentially associated with Big Five personality and attachment style. J Posit Psychol 2006;1:61-71.

29. MacDonald G, Locke KD, Spielmann SS, Joel S. Insecure attachment predicts ambivalent social threat and reward perceptions in romantic relationships. J Soc Pers Relat 2013;30:647-661.

30. Mikulincer M, Shaver PR, Bar-On N, Ein-Dor T. The pushes and pulls of close relationships: attachment insecurities and relational ambivalence. J Pers Soc Psychol 2010;98:450-468.

31. Davis D, Shaver PR, Vernon ML. Physical, emotional, and behavioral reactions to breaking up: the roles of gender, age, emotional involve- ment, and attachment style. Pers Soc Psychol Bull 2003;29:871-884

32. Simpson JA, Rholes WS. Handbook of Attachment: Theory, Research, and Clinical Applications. New York, NY: Guilford Press; 1999.

33. Schimmenti A, Bifulco A. Linking lack of care in childhood to anxiety disorders in emerging adulthood: the role of attachment styles. Child Adolesc Ment Health 2015;20:41-48.

34. Gauthier L, Stollak G, Messé L, Aronoff J. Recall of childhood neglect and physical abuse as differential predictors of current psychological functioning. Child Abuse Negl 1996;20:549-559.

35. Widom CS, Czaja SJ, Kozakowski SS, Chauhan P. Does adult attachment style mediate the relationship between childhood maltreatment and mental and physical health outcomes? Child Abuse Negl 2018;76:533-545.

36. Zietlow A-L, Nonnenmacher N, Reck C, Mueller M, Herpertz SC, Neukel C, et al. Early life maltreatment but not lifetime depression predicts insecure attachment in women. Arch Women Ment Health 2017;20:477-486.

37. Goodall K, Rush R, Grünwald L, Darling S, Tiliopoulos N. Attachment as a partial mediator of the relationship between emotional abuse and schizotypy. Psychiatry Res 2015;230:531-536.

38. Van Veen T, Wardenaar KJ, Carlier IVE, Spinhoven P, Penninx BWJH, Zitman FG. Are childhood and adult life adversities differentially associated with specific symptom dimensions of depression and anxiety? Testing the tripartite model. J Affect Disord 2013;146:238-245.

39. Spinhoven P, Elzinga BM, Hovens JGFM, Roelofs K, Zitman FG, van Oppen $\mathrm{P}$, et al. The specificity of childhood adversities and negative life events across the life span to anxiety and depressive disorders. J Affect Disord 2010;126:103-112. 